\title{
Ageing in place and the internet of things - how smart home technologies, the built environment and caregiving intersect
}

\author{
Phillippa Carnemolla(1)
}

\begin{abstract}
Smart technologies and the Internet of Things (IOT), have the potential to play a significant role in enabling older people to age in place. Although there has been substantial development of new applications of sensor technology in the home, this has tended to be tele-health focused, and there has been less work done on the role of loT and ageing in place that more broadly considers caregiving and the built environment. Research in the field of loT development and evaluation has recognised a number of challenges and limitations associated with past smart technology developments to support Ageing in Place, calling for user centeredness and better integration with broader systems. Compounding this, research into Ageing in Place and home environments has focused on built environments and largely ignored the impact of technology in the lives of older people staying at home. Recognising a gap in acknowledging the potential impact of technology on Ageing in Place theories, the purpose of this paper is to conceptualise a way of framing smart technology within an Ageing in Place model that acknowledges the interaction of smart technology with the built environment and caregiving and to present a framework for visualising the interactions that take place. A review of Environmental Gerontology model development is undertaken and a new model is presented that recognises the role of technology in Ageing in Place. Based on this model, a template is developed and three case studies of older people's experiences of smart home technology, home modifications and caregiving are mapped out. These are used to demonstrate "proof of concept" of the relationships put forward in the HAST model and the pre-curser for a template to help people map smart technology and its role in supporting caregiving and ageing in place. This paper's position is that technologies such as loT further support the role of the built environment and caregiving to produce outcomes that enable older people to remain autonomous, independent, safe and well at home. However, a number of risks were also identified through the case studies, the issues of maintenance, cost and ease of use, and willingness to use are considerations and potential barriers to the benefits of smart technology.
\end{abstract}

Keywords: Internet of things, Ageing in place, Built environment, Care, Self care, Socio-technical

\section{Main text Introduction}

The purpose of this paper is to provide other researchers and design developers with a way of visualising Internet of Things (IoT) systems as a part of the broader systems supporting Ageing in Place and considers the roles of the built environment and community caregiving. The paper explores the implications of introducing smart home technologies into the homes of older people who are receiving care- in terms of the impact on caregiving,

Correspondence: Phillippa.carnemolla@uts.edu.au

School of Built Environment, Faculty of Design, Architecture and Building, University of Technology Sydney, Sydney, Australia wellbeing, functional limitations and the built environment. This is a valuable investigation for the purposes of exploring innovative care solutions given the increasing pressure on the care workforce in ageing populations across the globe. It is also important for understanding the multi-dimensional interactions that impact outcomes for older people experiencing declining health who wish to remain living at home.

\section{The internet of things}

The Internet of Things (IoT) is a term that relates the connection of material devices to the internet - as diverse as domestic appliances to health monitoring equipment to 
$>$ vehicles. Once connected, each thing is attributed a unique network address making it identifiable. Its sensors mean that it has the capacity to register changes to its environment and transmit that information over the internet, as well as the potential to store and process information, or independently initiate action [actuation] (Yan, Zhang, Yang, and Ning, 2008). Applications of IoT have the potential to play a significant role in enabling older people to Age in Place. In this paper the IoT technology analysed is limited to smart home technologies devices that relate specifically to managing tasks in the home environment - and excludes health technology devices.

\section{Background: Ageing in place}

One of the challenges accompanying ageing populations is the increasing demand for care services (Cangiano \& Shutes 2010; Simonazzi, 2009; Bloom et al 2015). Australia is experiencing increasing levels of disability and functional impairment, due predominantly to its ageing population. Although health overall has increased, people are living longer with an increase in morbidities and functional limitations (Chatterji et al. 2015). A consequence of these morbidities and functional limitations is a propensity for lower levels of wellbeing and an increased demand for care.

Ageing in Place is a concept whereby older people are able to continue live in their own homes as they age despite changes to their health and mobility. There is considerable evidence that older adults prefer to live independently at home as they age rather than enter aged care facilities (Boldy et al. 2011; Eckert et al. 2004; Woolhead et al. 2004). As populations across the globe are getting older and living longer, the world life expectancy index is projected to further increase over the coming decades (Kontis et al, 2017). This acceleration of demographic ageing raises significant public health questions about how and where long-term care services are provided as the ageing process brings with it increasing dependence on care services. The economic benefits of supporting older adults to remain in their own homes and communities has also influenced policy makers and health providers as they avoid the costly option of institutional care (WHO 2007).

Research into Ageing and Place and built environments in the fields of health, environmental gerontology and built environment continues to identify and exploring the relationship between caregiving and housing for older people (Carnemolla and Bridge 2018). But to date, research in this area this has largely ignored how technology fits into this relationship.

This is despite the recognition of the increasing demand for integrated care provided in people's homes, and the acknowledgment of the role smart technologies can play (Morris et al. 2013).

\section{Technology and ageing in place}

Smart technologies and IoT are being developed to support the goals of Ageing in place (Iecovich 2014):

1. To enable older people to stay in their homes as long as possible allowing them to maintain independence and autonomy.

2. To give policy makers in aged care less expensive (and preferable) alternatives to institutional care

There is a diverse body of evidence exploring and supporting the development of IoT solutions to address issues facing older people, policy makers and service providers.

Despite many assistive technologies being developed to support older people in their homes, there is evidence of a lack of fit between older people's daily lives, their support needs, and the technologies and services available (Greenhalgh et al. 2015; Sanders et al. 2012, Gutierrez et al. 2017). There are additional challenges to using technology to support ageing in place, including low rates of adoption by older people the cause of which has been explained as poor interface design, issues of privacy and trust (Yusif et al. 2016) economic barriers and educational barriers (Wang et al. 2016; Satariano et al. 2014). A number of studies have proposed that future IoT development will require a more user centred and co-creative design approach (Azimi 2017; Gkouskos and Burgos 2017; Greenhalgh et al. 2015; van Hoof et al. 2011; Beringer et al. 2011, Wherton et al. 2015)) and age appropriate designs (Pietzrak et al. 2014). In addition to these considerations, more evaluation of IoT systems in the home of older people is needed (Peek et al. 2014; Reeder et al. 2013)).

\section{Considering adoption of technology}

Although smart home devices and systems hold considerable promise in assisting a people to age at home independently and autonomously, predicting technology adoption by older people is more complex and multifactorial than simply by chronological age or health status (Lee \& Coughlin 2015). Coupled with a need to improve user-centredness and integration of Iot in general, approaches are needed to support the development of designed IoT solutions that are relevant, adaptable and appropriate given the built environment and human-human care networks around it. Only then can IoT systems be properly evaluated, and disseminated to an increasingly diverse older population.

\section{Aims}

Although literature in housing and health is beginning to identify and measure the nature of the relationship 
between ageing in place, the built environment and caregiving (Carnemolla and Bridge 2018), and literature in smart technology is building foundations of also supporting ageing in place, there has been little articulation of how technology, caregiving and physical environments are related for older people who are ageing in place. An understanding of this inter-dependent relationship would allow ageing in place models to better align the technical, social and physical configurations of the homes of older people to support ageing in place (Procter et al. 2014).

This article has two aims - firstly it proposes a theoretical foundation that incorporates technology in established human/activity/space relationships. Prior to this article, the potential impact of technology has not been considered in such a holistic way that acknowledges interdependence. Secondly it develops a template, upon which to map the interactions of technology, health, built environment and caregiving. It applies three case studies to illustrate the template's application. It is intended that this template be shared for the purpose of encouraging much needed further research, including larger, statistically significant studies of ageing in place that encompass the technical, social and built environment characteristics of Ageing in place.

The first part of the paper includes the development of the Human/Activity/Space/Technology HAST model (Fig. 2) from established environmental gerontological theory. This aims to inform research and development practices of smart home technologies and ageing in place. In the context of the model development, hypothesis $\mathrm{H} 1$ is made.

H1: A demonstrable relationship exists between smart home technologies, built environment and caregiving in the homes of older people who are ageing in place?

Further, depending on the outcome of the establishment of a relationship, we also seek to determine.

What, if any, moderating factors/risks (specific to ageing in place) exist that impact on older people's health and wellbeing outcomes following the introduction of smart home technologies (IoT)?

Thus the HAST model is expanded to include a template for analysing case studies of IoT introduction into the home. The template is applied to three case study scenarios, which explore how specific IoT applications work with types of caregiving in the built environment to support ageing in place.

\section{Approach}

This paper examines and analyses the potential of smart technology to support caregiving in the home. It presents a way of visualising the role of smart technology within an Ageing in Place model that acknowledges the intersecting roles of community caregiving networks and the built environment. It is intended to provide an exploration of relationships and an examination of potential risks and will support researchers, engineers and design developers to consider the broader, socio-technical context that IoT systems play in a system of Ageing in Place (Storni 2010; Procter et al. 2014; Sun et al. 2009). Sociotechnical solutions acknowledge the contribution that groups beyond an engineering community (e.g. scientists, policy makers and users) can make, and address the risk of narrower engineer focus in solving engineering problems with broad social impact and significance (Bijker 1997). This is a valuable investigation for the purposes of exploring innovative solutions to escalating care needs as populations age at home.

The research is undertaken in four main parts within this paper:

1. The relationship between Ageing in place and the Internet of Things is explored via a review of IoT applications specifically designed for Ageing in Place. Ageing in Place is described in terms of Actor Network Theory (ANT) in order to understand the interactions taking place between person, built environment, carers and technology.

2. A review of Environmental Gerontology model development is undertaken and a new model development is proposed. This new model development is referred to as the human/activity/ space/technology (HAST) model

3. A template based on the interdependent factors in the HAST model is developed for the purposes of testing how the introduction of IoT can be analysed.

4. An analysis of three actual case studies is undertaken, using the developed template, in order to explore the ways IoT intersect with the caregiving activities in the home and reveal any resulting complexities following the introduction of IoT. Each case study is presented using the template.

\section{Limitations and further research}

This is an explorative initial study and our findings are based on limited data, however results from the use of the templates imply that technology is interdependent across caregiving, wellbeing and the built environment. Therefore there is opportunity for further research in the form of a more detailed research design with greater statistical significance and control. Having a control would provide greater internal validity for any effect size calculations, as effect sizes from uncontrolled designs tend to be higher than effect sizes from studies conducted with control groups.

\section{The intersection of ageing in place and loT}

Sicari et al. (2016) characterise IoT systems as a collection of smart devices which interact on a collaborative 
basis to fulfil a common goal, acquiring data from and acting upon the environment they are in. Based on this understanding, in the context of Ageing in Place, an IoT system in the home of an older person will have the inherent goal of supporting an older person to live a socially connected, well, independent and safe life at home and in the local community.

Technology applications that support ageing in place are diverse in their purpose and their design. Research by Rantz et al. (2013) describes sensor technology as working in alignment with ageing in place three ways;

1. Monitoring health status Peetoom et al. 2015; Kaye et al. 2011; Dodge et al. 2012; Cesta et al. 2011)

2. Detecting emergencies Gill et al. 2016

3. Notifying healthcare providers of changes in health status Kleinberger et al. 2009

Beyond an e-health or tele-health focus, there are other opportunities for IoT technologies to address the barriers faced by older people as they Age in Place in their homes in the following additional ways:

4. Automating daily tasks and home maintenance (Fausset et al. 2011; Ghazal and Al-Khatib 2015)

5. Reminding and prompting older people to support independence and safety daily life despite cognitive decline (Nauha et al. 2016; Gibson et al. 2015; Lorenz et al. 2017

6. Enable communication and connection with broader social and caregiving networks

7. Transport and Navigation support

\section{Broadening the focus, identifying the actors}

There is a strong focus on the role of the built environment (housing) and support or care provision in the architectural, sociological and gerontological aging-in-place research (Bayer \& Harper, 2000; Judd, Olsberg, Quinn, Groenhart, \& Demirbilek, 2010), and can directly infuence weelbeing and health related quality of life (Carnemolla \& Bridge, 2016). Interestingly, this focus has not translated across to IoT literature related to Ageing in Place.

When rethinking our conceptualisation of IoT, toward solutions to Ageing in Place, a first step is to identify what and who is influencing the successful integration of a new IoT technology application in an Ageing in Place setting. To do this, an Actor Network Analysis was undertaken (Fig. 1). Actor Network Theory (ANT) enables the delineation of a set of actors (the network) that influence, shape or determine an action [30], which facilitates the identification of relationships within and between actors in the same or different networks (Seuwou et al. 2017; Rhodes 2009). It recognises both human and non-human (material) actors as significant to the network. An ANT-based approach is

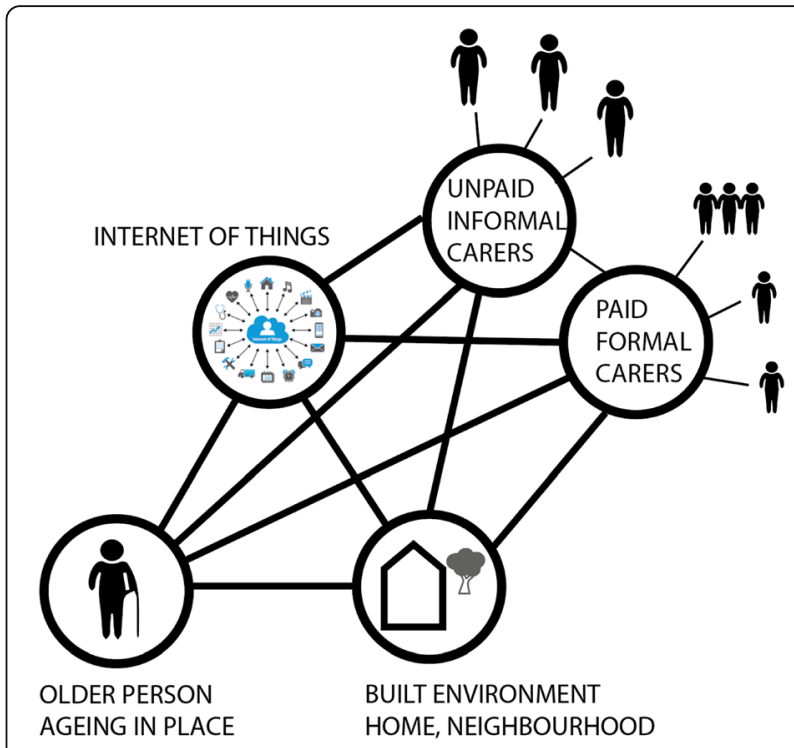

Fig. 1 Actor Network Theory (ANT) analysis of Ageing in place with loT

conceptually useful in helping to appreciate the complexity of caregiving networks involved in Ageing in Place as well as the active role of technology and built environment in this context. It aligns with Winance (2010) conceptualisation of ageing, caregiving and assistive technology as "shared work". ANT approaches are commonly applied to health services delivery (Cresswell et al. 2010) but have tended to exclude the role of the built environment.

Figure 1 illustrates the interconnectedness of all actors in an Ageing in Place setting, the older person, their multiple care networks, their built environment IoT technology systems.

\section{Caregiving, loT technology and the built environment}

The physical built environment of housing is an important consideration in frameworks or models of smart technology, digitised service models, or IoT because it is an older person's changing relationship with the physical environment around them that triggers the need for care provision at home - and opportunities for IoT solutionsin the first place. It is the dependence on care in an Ageing in Place scenario that is both the most costly aspect -for health providers, and on human capital. And central to the person who is ageing in place, a dependence on care can lead to a loss of dignity and wellbeing.

Research by Proctor et. Al identified stakeholders and explored the nature of relationships that develop in order for "ageing in place" to succeed. This research found that ageing in place is something that is -co-produced. That is - it involves a collaborative effort from the older person, and their informal care networks (family, friends) and formal care networks (paid care workers, therapists, medical practitioners etc.). Therefore, any 
model of IoT designed to support ageing in place should recognise this collaborative effort by identifying the types of caregiving that intersect with the technology being developed. The following paragraphs identify the types of care involved in successful ageing in place;

Care is a broadly used term used in many contexts and as such it has various meanings and associations. As a result, the definitions and boundaries around care types are not always clear. This paper understands the term care as it relates to ageing in place; an older person with reduced level of functional ability, living in their own home. Care-giving in this sense can be paid or unpaid and provided by partners, family, friends, private consultancies or government departments. Care types are distinguished from one another by factors such as where the care is provided, who provides it and what type of assistance is given. For example, care can be lighter domestic assistance (housework), personal care (to wash or toilet) or medical care. These variants are further explored in Table 1 with definitions.

A review of these definitions reveals that community care provided in the home to support ageing in place encompass formal, informal and self-care among the care types delivered in a home environment and community setting. Because care can involve a wide range of activities, from general help in the home to administering medical care, it is unsurprising that a wide range of funded services constitute funded community care in Australia.

Community care can be divided into three main types - formal, informal and self-care - distinguished by who provides and/or pays for it. Formal care includes funded home care services, such as those delivered by Home and Community Care. "Formal care is regulated care delivered in either residential or community settings, including the person's own home" (Australian Institute of Health and Welfare, 2007, p. 493). Most formal care is funded through government programs but may also be purchased privately Informal care refers to the network of unpaid care provided within the community, typically by family, friends and neighbours; self-care is a less common term that refers to techniques for self-managing or adapting in order to care for oneself in the context of functional limitations. "An informal carer is considered to be a person, such as a family member, friend or neighbour, who provides regular and sustained care and assistance to the person requiring support, usually on an unpaid basis." (Australian Institute of Health and Welfare, 2007, p. 493). Self-care has no universally agreed definition, possibly because it can be applied in diverse medical circumstances (Levin, Katz \& Holst, 1976; Van Der Geest, 1987); however, in the context of community care it often refers to the ability to provide care for oneself. The longest-standing definition is as follows: "Self-care in health refers to the activities individuals, families and communities undertake with the intention of enhancing health, preventing disease, limiting illness, and restoring health. These activities are derived from knowledge and skills from the pool of both professional and lay experience. They are undertaken by lay people on their own behalf, either separately or in participative collaboration with professionals." (p.2) (World Health Organization, 1984).

\section{Review of environmental gerontology theory}

For over a century, literature in the fields of management and vocational behaviour has examined the adaptability of the person to the environment (Parsons, 1909; Pervin, 1968; Schneider, 1987), giving rise to specialist areas of study such as environmental gerontology. Environmental gerontology focuses on the description, explanation, modification or optimization of the relation between older people and their socio-spatial surroundings (Wahl \& Weisman, 2003) and therefore encompasses the housing arrangements and assistive technology (including IoT) of older people.

Longstanding research in the field of Environmental Gerontology (EG) has established a relationship between environment and behaviour as people age. EG emerged from the psychology domain during the 1960s with Powell Lawton's environmental press paradigm, which applied to empirical research and design of built environments. Lawton and Nahemow's Press Competence model also became a landmark theoretical development in EG, contributing to a theoretical understanding about the interaction between a person's competence to perform an activity or behaviour and the environment (Lawton \& Nahemow, 1973).

The significance of EG research to this understanding of IoT and Ageing in Place is twofold; first, EG continues to recognise that the design of the built environment, particularly people's home environment has the capacity to enable a person to perform daily tasks. Technology can be considered as an enhancement of this built environment relationship. Second, the built environment has the potential to have a major impact on the behavioural and emotional functioning of older people, thereby impacting on health, wellbeing and independence. Technologies such as IoT do not replace the role of the built environment, for example, they do not replace the need for home modifications to enable ageing in place (van Hoof et al. 2011), rather they work in tandem with the built environment and caregiving to produce outcomes that enable people to remain autonomous independent, safe and well at home.

\section{Rethinking environmental gerontology models to describe ageing in place with technology} Ongoing work by Bridge (2008) and (blinded for review) (2015) has further developed classical EG theory to 
Table 1 Definitions of care types

\begin{tabular}{ll}
\hline Care Type & Where is this type of care provid \\
\hline Community Care & $\begin{array}{l}\text { In a community setting e.g. at } \\
\text { home or community day care }\end{array}$ \\
& \\
Formal (waged) & $\begin{array}{l}\text { Can be provided either in a } \\
\text { registered nursing home or } \\
\text { residential care institution OR } \\
\text { In a community setting e.g. at } \\
\text { home or community day care }\end{array}$
\end{tabular}

Informal (unpaid) In a community setting e.g. at care home or community day care

Self-Care
Not limited by location
Paid care workers

Unpaid family or friends/informal network

Oneself
Definition/Explanatory notes

By either family or friends (informal), or by paid care workers (formal or waged)

Community care is loosely defined as care based in a community setting (Khoosal \& Jones, 1989) and can be provided in a variety of formats, including formal, informal and (the lesser-researched) selfcare. Community Care is the provision of care and support for people who want to stay independent and living at home for as long as possible.

Formal care includes waged care services such as those delivered by Community Care Services: 'Formal care is regulated care delivered in either residential or community settings, including the person's own home. Most formal care is funded through government programs but may also be purchased privately.' (Australian Institute of Health and Welfare, 2007, p. 493).

Informal care refers to the unpaid services provided by family, friends and neighbours:

'An informal carer is considered to be a person, such as a family member, friend or neighbour, who provides regular and sustained care and assistance to the person requiring support, usually on an unpaid basis.' (Australian Institute of Health and Welfare, 2007, p. 493).

Self-care has no universally agreed definition. However, in the context of community care it often refers to the ability to provide care for oneself. The longest standing definition is as follows:

'Self-care in health refers to the activities individuals, families and communities undertake with the intention of enhancing health, preventing disease, limiting illness, and restoring health. These activities are derived from knowledge and skills from the pool of both professional and lay experience. They are undertaken by lay people on their own behalf, either separately or in participative collaboration with professionals.' (World Health Organisation, 1984, p. 2)

There are four types of support for self-care: (1) as sistive technology; (2) environmental changes (which include home modifications); (3) behavioural adjustments (e.g. avoid stairs) to overcome impairments (De Friese, et al., 1994). Education and training also plays an important role in helping a career better understand the full potential of these supports. Assistive Technology can be broadly defined as 'devices and techniques that can eliminate, ameliorate, or compensate for functional limitations' (Pope and Tarlov, 1991, p. 225) encompass a trio of interdependent variables relevant to a person Ageing In Place: Human/Activity/Space (HAS). This HAS model was articulated to visualise the process transactions that take place when ageing and receiving care in a home environment. Where earlier Environmental Gerontology models identify the older person and the environment as interdependent; the incorporation of the activity into the human/activity/space model recognises the relationship between the 'doing' within the environment. It has enabled the modelling of interdependence of the older person, their built environment and the performance of tasks.

Bringing technology into this model adds a new dimension of interdependence with the potential to enhance the human, activity and space relationship in new ways - this is the Human/Activity/Space/Technology model (HAST). A diagram of the HAST model for Ageing in Place with technology is illustrate in Figure following (Fig. 2).

One way of interpreting the relationships illustrated in Fig. 1 is that a change in personal health (human) will influence whether and how an activity can be performed; a change in built environment (space) will also impact whether and how an activity is performed, and that forms of smart home technologies including IoT, will support and enhance the relationships across all three theoretical components. Innovation, and new technology that considers the interdependence of the built 


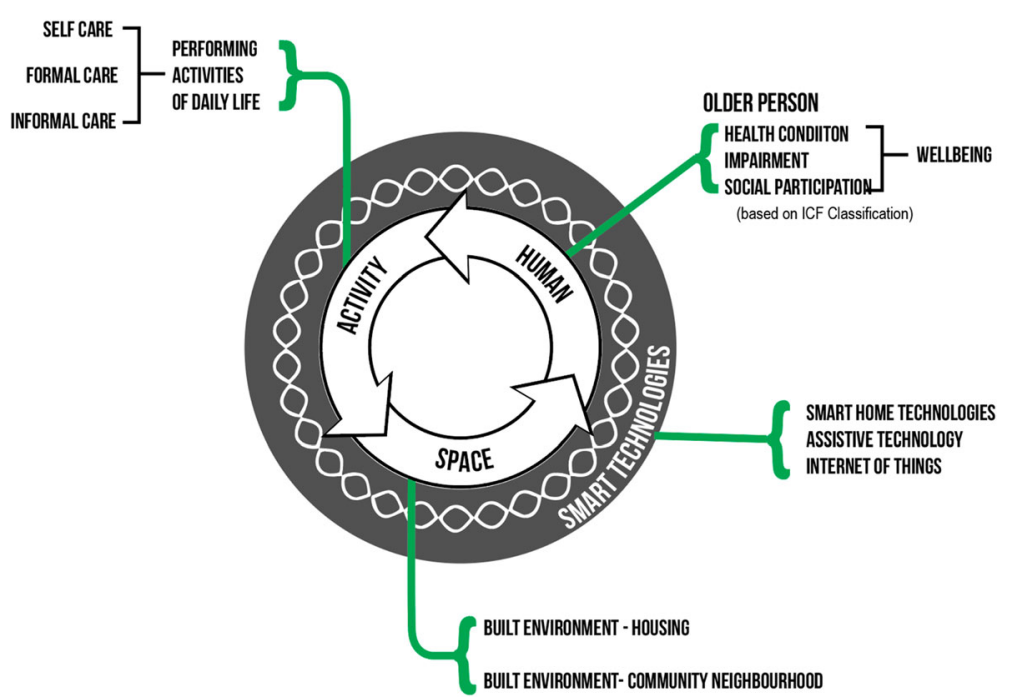

Fig. 2 Conceptual Analysis of Ageing in Place as a development of Human/Activity/Space/Technology model (HAST)

environment with independence and caregiving as people age can facilitate the boundary shift toward new self-care configurations.

\section{Case studies -applying template design}

To visually represent how the role of IoT interacts with older people's experience of their built environment and care relationship a template has been designed to apply each case, and to analyse and compare the potential impact of IoT on individual care cases. The template has been designed based on the interdependent relationships identified in the HAST model - health, care, smart home technologies and the built environment.

The utilisation of a template to visualise and analyse the impact of environmental change on caregiving was first undertaken by Carnemolla \& Bridge (2011) in their report analysing the potential for home modifications to substitute for care service in the home. This paper draws on that approach and builds upon the template format to include an examination of smart home technologies. Unlike the Carnemolla \& Bridge report, this paper does not examine the cost implications, rather this template is focused on the impact of the introduction of IoT in the home on caregiving practices.

The template is essentially a road map for analysing the multidimensional setting of technology and ageing in place, given the context of changes in health and caregiving associated with it. The case study template designed for this research is maps impact of the introduction of a new technology on care needs, wellbeing and independence of an older person living at home. It also provides an opportunity to document some of the complexities and limitations experienced by the older person, their families and carers in implementing and using the technology.
The template consists of seven blocks, into which parts of the data/narrative of the case study are inserted. These include; personal profile, care profile, functional limitations, built environment, smart home technology, outcomes and case study highlights. These sections are numbered in the following diagram (Fig. 3):

1. The personal profile maps the older persons situational/health/functional profile and highlights the current formal and informal care needs.

2. The Care Profile documents the care needs (formal and informal) prior to the technology being introduced.

3. The functional limitations module provides a way of illustrating the implications of a person's health status on their ability to be independent at home. The figurative ideogram of human form with functional annotations used in the template was originally developed for the Carnemolla \& Bridge (2011) report, and draws upon the original enabler ideogram by Steinfeld et al. (1979) (Fig. 4)

4. Built Environment documents any home modifications received in the home and lists the barriers the person has faced in their home environment that may be preventing them from undertaking tasks independently. It incorporates descriptive information about the environments where care is required.

5. The Smart Home technology section introduces the smart technology into the picture and explains which specific activities in the home that it is designed to support. As well and the context of it being introduced into the home - who instigated it, how long for and has it been successfully used. The technology analysed is limited to smart home 


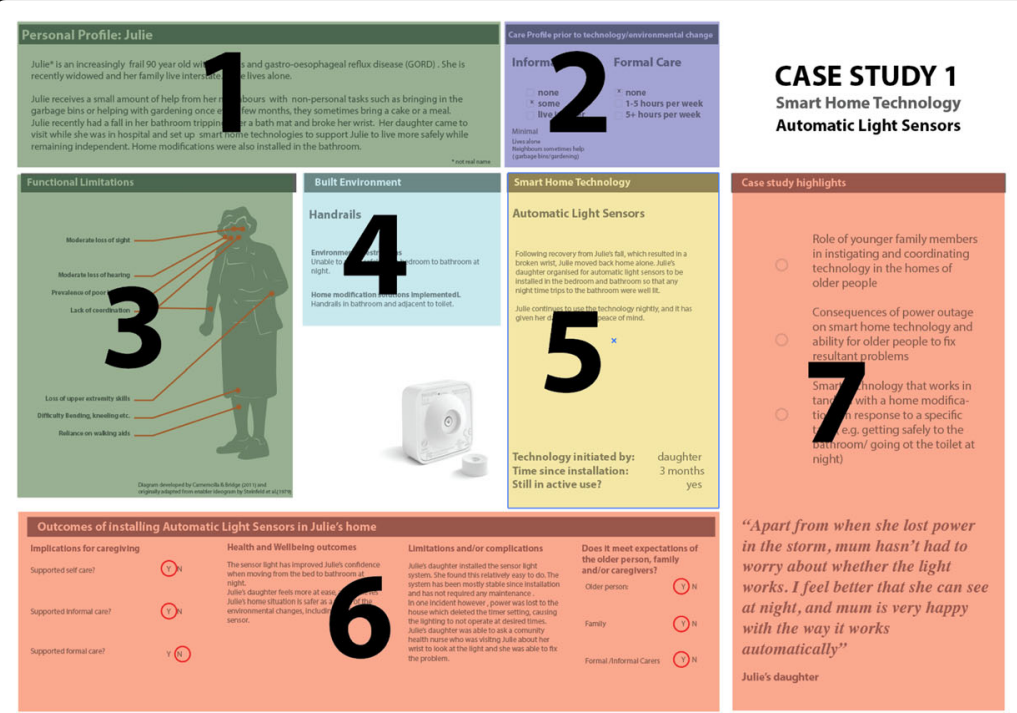

\section{1. personal profile}

2. care profile

3. functional limitations

4. built environment

5. smart home technology

6. outcomes

7. case study highlights

Fig. 3 Map of the template sections and how they relate to the HAST model

technologies - devices that relate specifically to managing tasks in the home environment - not health technology devices.

6. The outcomes section synthesises the results of the collected data and documents the impact of the technology in terms of caregiving, health and wellbeing of the older person as well as the impact

\section{Functional Limitations}

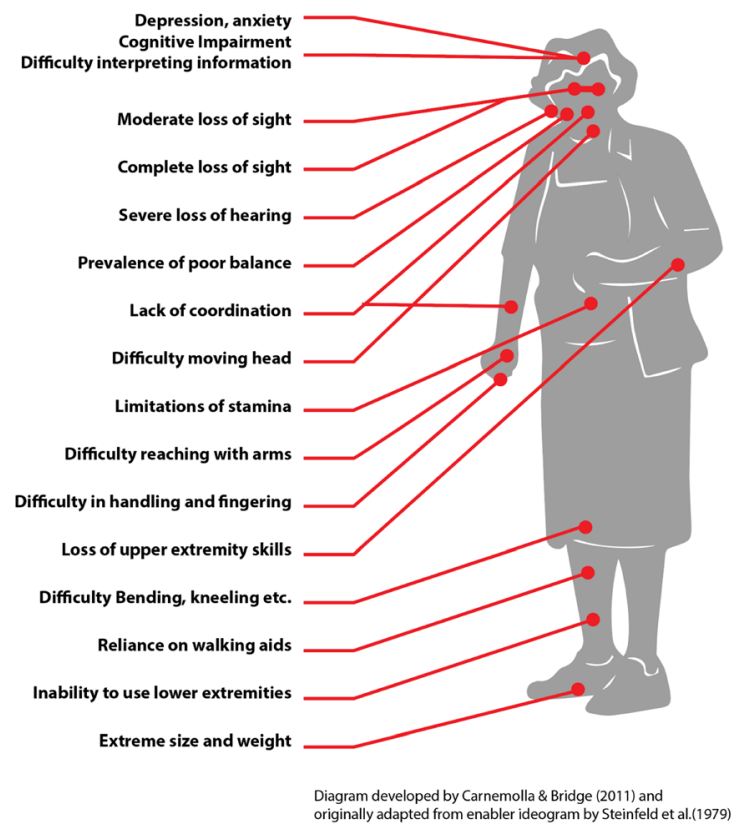

Fig. 4 Diagram used to map functional limitations in the template. Developed in Carnemolla \& Bridge (2011) and originally adapted from Steinfeld et al. (1979) on any carers. Any limitations of the technology as experienced by the older person and family are documented, and whether expectations of the technologies benefits have been met.

7. Case study highlights provides a synopsis of the broader implications raised in the particular case study around the relationships between technology, built environment, care, health, and wellbeing that may warrant further research and discussion.

\section{How the template maps the HAST model}

Blocks one to five represent specific elements within the HAST model, with blocks six and seven providing synthesis of the data and relationships revealed and highlights from each case study. How each HAST component is mapped in the template is shown in the following diagram (Fig. 5):

\section{Case studies}

In order understand how IoT can interact with care giving in the home, three actual case studies were selected to be analysed and applied to the template. This will reveal the impact of IoT and also test the potential for the template to demonstrate the impact of IoT for future studies and the HAST theory.

Three case studies were chosen for analysis from a research sample of community care recipients included in a larger Australian study of community care recipients. All in the study sample were older people currently receiving care in the home. Participants were asked to describe the impact of home modifications, care and smart technology on their wellbeing and care needs. In two of the three cases, a family caregiver (son or daughter) responded on behalf of their family member. 


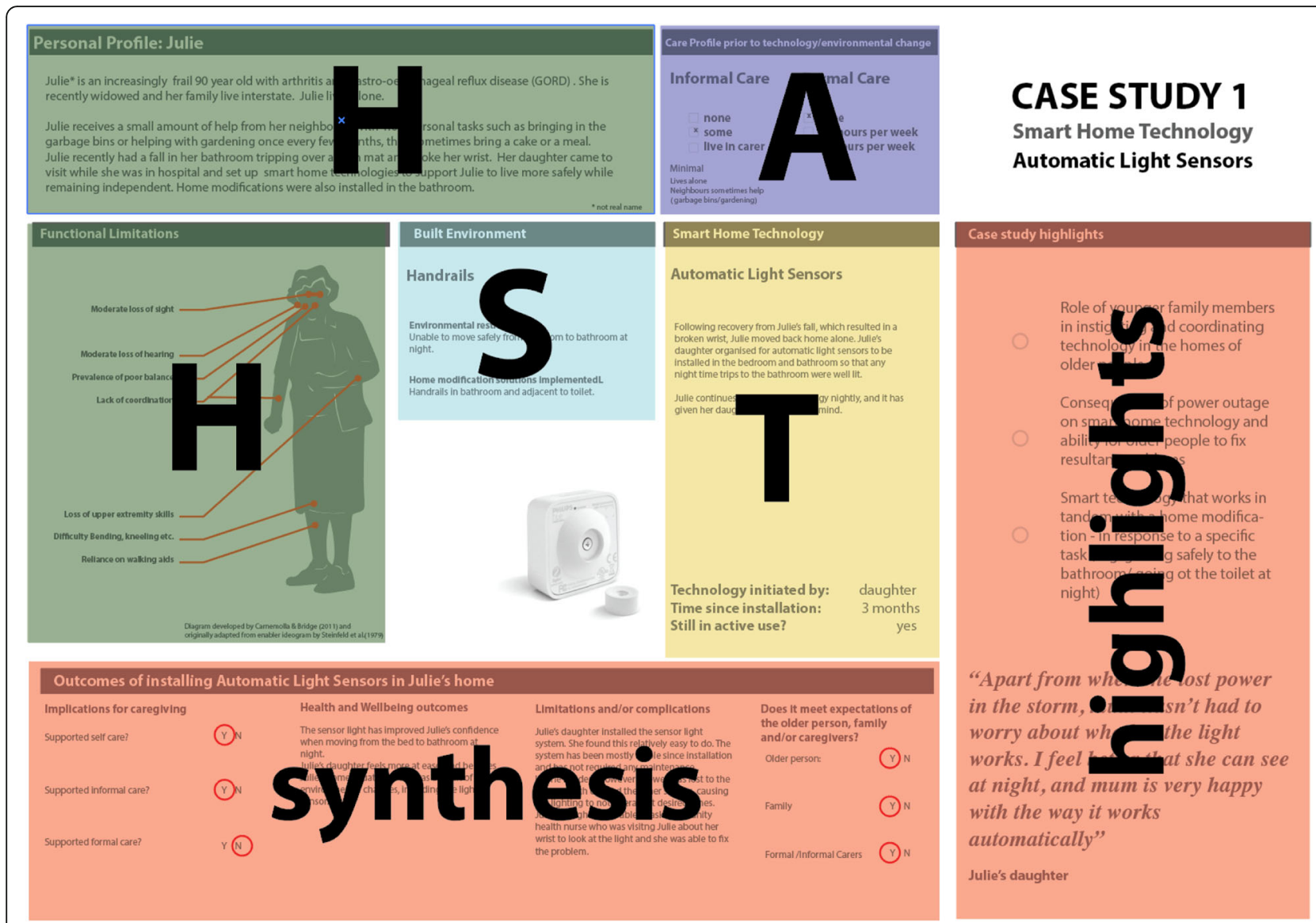

Fig. 5 Mapping the components of the HAST onto the template content

The technologies included in the case studies are diverse and include automated lights, a video doorbell/lock and a robotic lawn mower. All three technologies have the capacity to exchange data over the internet.

The case studies explore how specific IoT applications work with types of caregiving in the built environment to support Ageing in Place. These are framed as related data in the form of the types of support, smart home (IoT) technology, built environment and human-to-human care service. They provide a map of how these components interact to enable older people to manage difficult tasks safely and independently, remain independent and safe at home.

\section{Results: Three case studies using the template}

The following three Figures form the basis of the case study analysis and comparison between the experiences of three different older people, all of whom were requiring some kind of informal or formal support prior to the introduction of their smart technologies. All three are older than 75, and experiencing health complications associated with ageing. The case studies outline the following

- the health status of the older person,
- the care needs before and after the technology was introduced,

- the environmental limitations within the home including any home modifications received

- the reasons behind the technology being introduced including who instigated the technology

- outcomes of the technology in terms of care and wellbeing

- limitations and expectations around the technology and whether these have been met by stakeholders

- Highlights from the case study relevant to the HAST relationships and risks

\section{Case study 1: Julie (Fig. 6)}

Smart technology being examined

Automatic Light Sensors.

\section{Julie's profile}

Julie* is an increasingly frail 90-year-old with arthritis and gastro-oesophageal reflux disease (GORD). She is recently widowed and her family live interstate. Julie lives alone. 


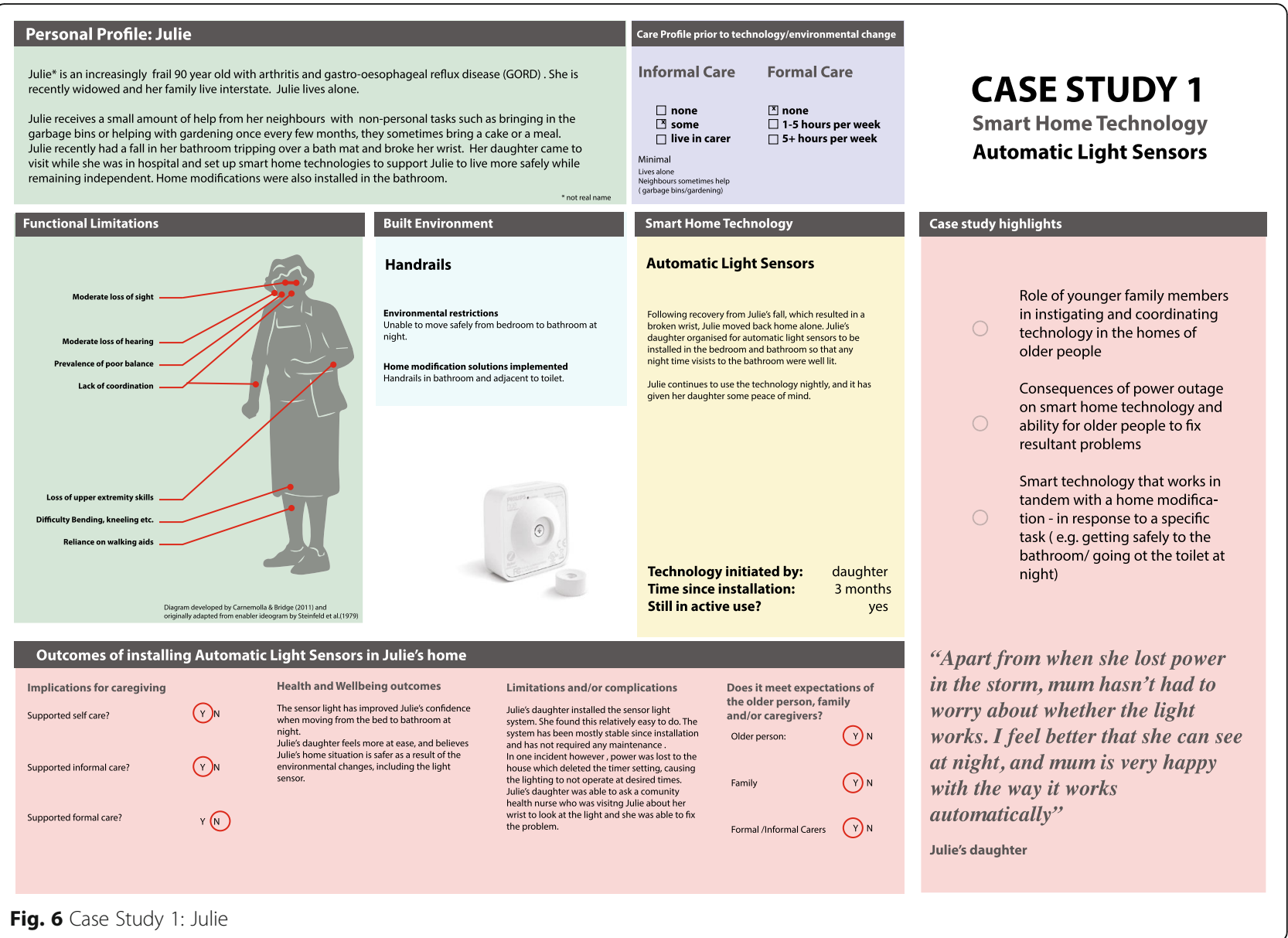

Julie receives a small amount of help from her neighbours with non-personal tasks such as bringing in the garbage bins or helping with gardening once every few months, they sometimes bring a cake or a meal.

Julie recently had a fall in her bathroom tripping over a bath mat and broke her wrist. Her daughter came to visit while she was in hospital and set up smart home technologies to support Julie to live more safely while remaining independent. Home modifications were also installed in the bathroom.

\section{Julie's outcomes}

Julie's outcomes have been positive. The sensor light has improved Julie's confidence when moving from the bed to bathroom at night. Julie's daughter feels more at ease and believes Julie's home situation is safer as a result of the environmental changes, including the light sensor.

\section{Highlights for further investigation and pattern finding} Julie's case analysis has raised a number of considerations about how technology is introduced, how external influences are handled and how technology coexists with seemingly unrelated built environment changes (the light system and the bathroom handrails). Highlights for broader consideration include:

- Role of younger family members in instigating and coordinating technology in the homes of older people

- Consequences of power outage on smart home technology and ability for older people to fix resultant problems

- Smart technology that works in tandem with a home modification - in response to a specific task (e.g. getting safely to the bathroom/ going to the toilet at night)

\section{Connection to the internet}

The technology has the capacity to be connected to the internet to control lighting remotely. In Julies' case this was not the most valuable attribute of the IoT technology. Rather the automation of the lights, the linking of her movements to the built environment and the removal of the need to seek out the light switch, where what Judy and her daughter found most valuable. 


\section{Case study 2: Sarah (Fig. 7)}

Smart technology being examined

Video door bell lock.

\section{Sarah's profile}

Sarah"is a 79 year old being treated for breast cancer and diabetes. Sarah lives alone. Sarah does not have any children, but does have nieces and nephews who live in surrounding suburbs. They check up on her from time to time but do not provide regular care - they have been called a number of times by formal support providers that they couldn't rouse Sarah to open the door. Sarah's mobility is limited due to peripheral neuropathy. She has been experiencing some anxiety and this has been heightened because of regular door knockers asking for money or selling items. She also finds it very difficult to get to the front door quickly when the door bell rings. Sarah's nephew suggested an automated video door bell and lock system as a form of smart home technology to support her to live comfortably at home.

Sarah receives $5 \mathrm{~h}$ of formal care per week for help with showering since her surgery and some domestic support at home.

\section{Sarah's outcomes}

Sarah's outcomes were mixed, in one sense her anxiety has been reduced as her nephew now screens all visitors remotely, however the technology has not necessarily supported her self care. Since the video doorbell has been installed, Sarah's health declined. The features of the technology have not been used to their potential because of Sarah's reluctance to use the technology now. This is possibly lack of confidence and also some frustration at not being able to work out some features.

Sarah prefers to give trusted and regular carers a key to the back door. But casual carers still use the technology being let in the front door remotely by Sarah's nephew. A lot of Sarah's anxiety stems around being able to get to the door if the door bell rings, and also feeling vulnerable if she opens the door to a salesperson or door-knocker asking for money for a charity cause. Her mobility is declining.

Sarah was very happy with the system to start with. She was also happy being able to screen the front door. Sarah's nephew has now taken on the screening of visitors via the app. But he said without the app, it would be causing a lot of stress to Sarah and she probably couldn't remain living in her home.

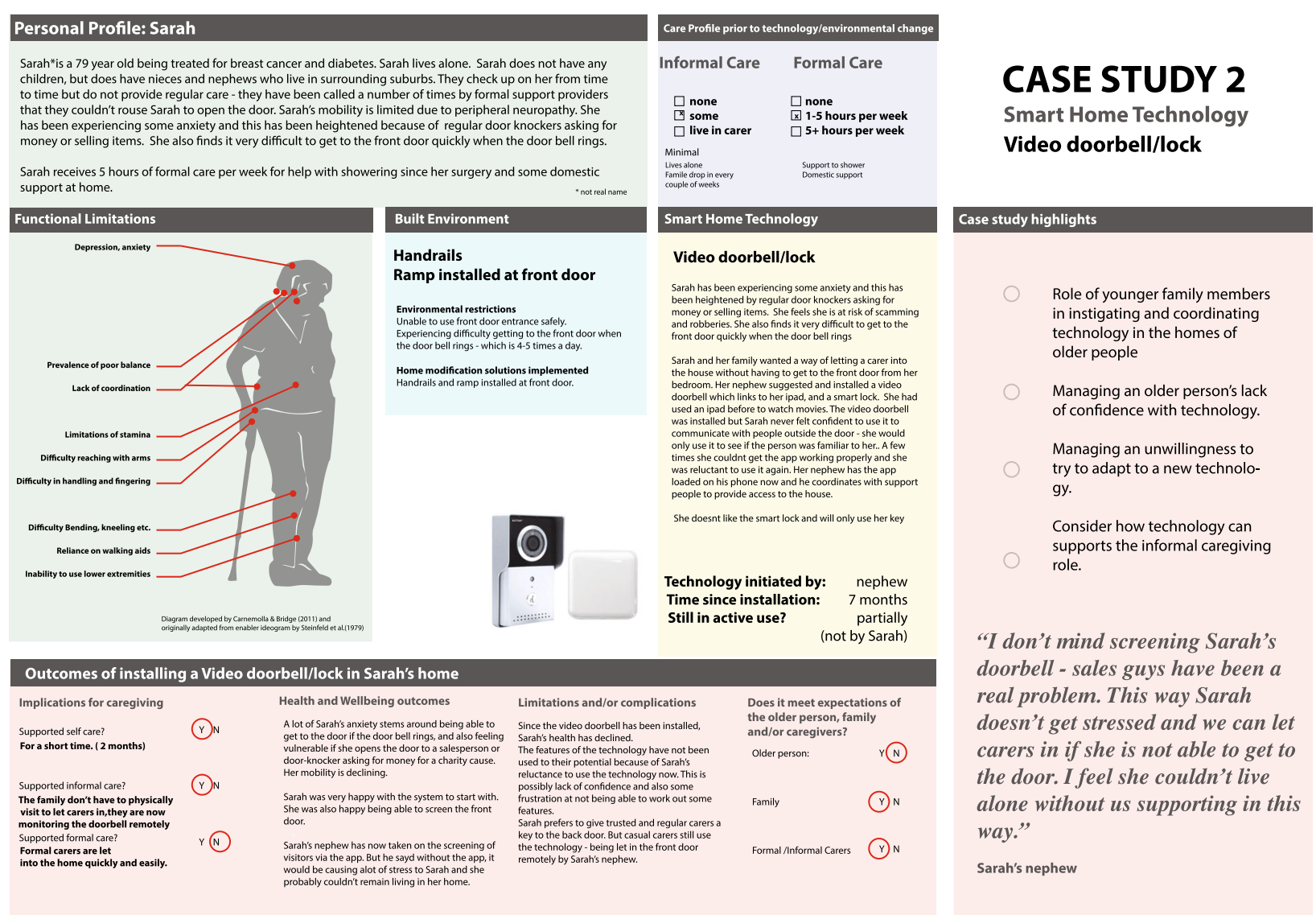

Fig. 7 Case Study 2: Sarah 


\section{Highlights for further investigation and pattern finding}

Although Sarah's outcomes were mixed, the case study reveals some critical risks and limitations when introducing new technologies into the homes of older people. Some of the highlights synthesised from Sarah's case in the template include:

- Role of younger family members in instigating and coordinating technology in the homes of older people

- Managing an older person's lack of confidence with technology.

- Managing an unwillingness to try to adapt to a new technology.

- Consider how technology can supports the informal caregiving role.

\section{Connection to the internet}

The connectivity to the internet is an attribute of this technology that is highly valued in this context. It enables the remote screening and control of security, meaning Sarah's wellbeing is maintained and her nephew is able to provide decision making support without living with Sarah.

\section{Case study 3: John (Fig. 8)}

\section{Smart technology being examined}

Robotic Lawn Mower.

\section{John's profile}

John $^{*}$ an 82-year-old being treated for chronic obstructive pulmonary disease (COPD). John lives with his wife Norma. John recently lost his driver's licence. Norma provides all of John's informal care, drives him to appointments, cooks for him, cleans the house.

John uses a walker outside of the house. John has been feeling depressed since losing his licence and frustrated as he cannot do many of the household tasks he expects of himself. As a high profile member of the community, the local Rotary Club donated funds for John to purchase a robotic lawn mower to maintain his once pristine garden.

\section{John's outcomes}

John's outcomes in terms of maintaining autonomy, independence and dignity have been very positive for him and his family. He has been able to continue to play his expected role in his family - a significant contributor to quality of life. The built environment changes lay an important role in collaboration with the new technology in fact John could not get out into the garden to operate the lawn mower without the ramp.

One significant concern however is the financial burden of maintenance of the lawn mower. John is worried about how he will afford to maintain it if there is a problem. He also worries it might get stolen and could not afford to replace it. This raises the significant consideration of how older people on limited incomes are expected to afford the regular and ongoing maintenance of technology designed to support them.

\section{Highlights for further investigation and pattern finding}

John's case study highlights to role of technology in supporting wellbeing, and how maintaining autonomy can mean that expected family roles can continue despite changing health needs. Highlights that emerge from the case study include:

- Smart technology that works in tandem with a home modification - in response to a specific task (e.g. accessing the garden safely/ mowing lawn)

- How do older people on limited incomes afford to buy and maintain new technologies?

- Consider the difficulties an older person might have when the technology needs maintenance- how to afford it, who to go to?

- Consider how smart technologies can support selfcare and independence with the outcome of improving wellbeing by lifting sense of worth and autonomy.

\section{Connection to the internet}

This technology is able to be operated remotely over the internet via an app. John did not use or highly value this aspect of the technology however. What was most valuable to John was the automation of the mowing task that it enabled, an important activity in the home that he himself was unable to perform because of his changing health.

\section{Discussion}

The data analysed in the three case studies and displayed using the template in Figs. 5, 6 and 7 provides the basis for refuting the null hypothesis; "There is no demonstrable relationship between between smart home technologies, built environment and caregiving in the homes of older people who are ageing in place".

\section{Evidence for the HAST model}

In order to explore whether the HAST theory holds in a setting for ageing in place, the three case studies are real life examples of technology being introduced into the homes of older people, with the implications, limitations and outcomes mapped on to the template design. The three case studies each reveal different aspects of the nature of the complex relationships that occur between care (activity), a person's functional capacity (human), smart technology (technology), and the built environment (space) for older people living at home. They also reveal a 


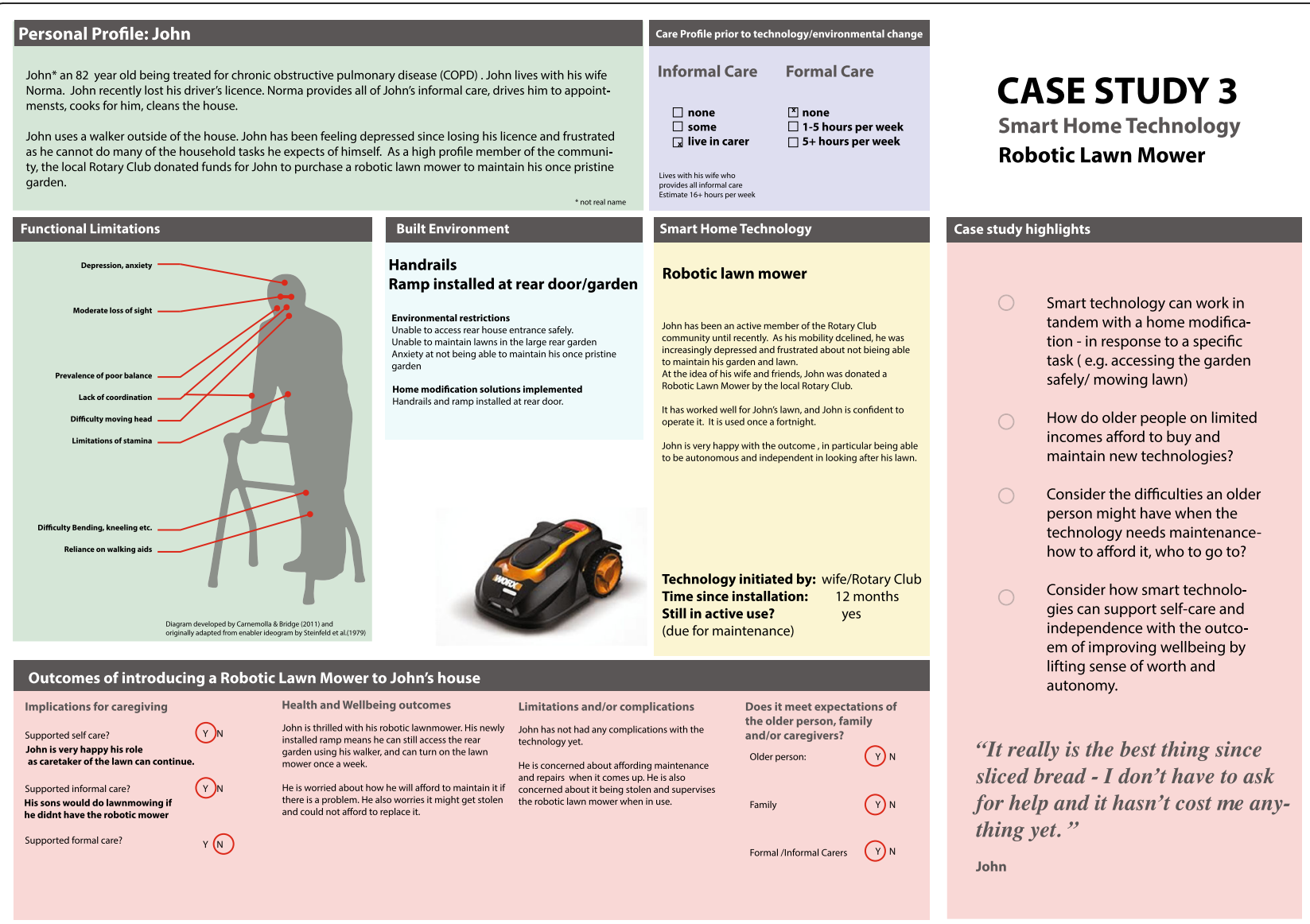

Fig. 8 Case Study 3: John

number of moderating factors that require consideration and impact whether the outcomes will be a positive one for the older person and their family and carers.

\section{Evidence of the relationships}

It is clear from the case studies that a relationship between smart home technologies and built environment does exist in ageing in place contexts. For instance, Julie's Automated lighting directly influences light levels in the built environment at night time, John's robotic lawnmower operates directly on the built environment (garden lawn). These is also evidence that home modifications and smart home technologies work in sync with one another to support a particular activity - the automated lights and installed handrails together make Julies tasks of getting from the bed to bathroom safer at night. John's ramp enables him to physically access the rear garden to activate his robotic lawn mower, Sarah's video door bell enables her to see who is at the door and let the person in without having to walk across the room.

Similarly, the case studies reveal that a relationship exists between smart home technologies and caregiving. Smart home technologies can change the way care is provided, as in Sarah's nephew being able to remotely screen people at Sarah's door. Or they can eliminate the need for some informal care activities - as in John's robotic mower meaning his son's didn't have to do it for him. Or smart home technologies can simply support carers by giving peace of mind, as in Julie's automated night light. Julie's daughter perceived the use of a night light made Julie much safer at home at nights.

Finally, the case studies support the existence of a relationship between the person's functional status and the use of smart home technologies - it was Sarah's limited mobility that triggered the consideration of a remote lock and door bell system, it was John's loss of mobility that triggered the suggestion of a robotic lawn mower, and it was Julie's fall and declining balance that triggered Julie's daughter to implement an automated lighting system in conjunction with home modifications in the bathroom.

\section{Risks}

The case studies reveal a range of limitations and risks associated with the introduction of smart technology in the homes of older people who may be experiencing declining health due to age related conditions. These risks 
directly relate to the outcomes of the technology - such as whether it continues to be used and maintained, whether it reaches its potential to support care and wellbeing of the older people it was installed for. These risks, including the case studies where they emerged, include:

- An older person's unwillingness to learn a new technology (Sarah had difficulties using the iPad interface for her video door bell)

- An older person's lack of confidence with technology (Sarah didn't trust herself to operate the technology interface and became frustrated)

- inability to maintain the technology (John's fear for his Robotic Mower)

- an older person taking a dislike to the technology due to frustration or fear (Sarah's experience with her video doorbell)

- an older person not being able to afford to continue to maintain or replace the technology (John's experience with his donated $\$ 2500$ robotic lawnmower.)

- a power outage - particularly when an older person is not trained to reset the technology (as in Julie's experience with her timing system on the automated lighting)

\section{Conclusion}

The purpose of this paper is to examine the nature of Internet of Things (IoT) systems as a part of the broader system supporting ageing in place, and to consider the roles of the built environment and community caregiving. It does this firstly by establishing the extent of actors in the Ageing in Place Network and incorporating those into a new HAST model of Ageing in place with technology. The HAST model is founded in established environmental gerontology models of ageing in place. In doing so the article contributes to theoretical developments in IoT and ageing fields.

The three case studies provide evidence of each of the specific relationships proposed in the HAST model, namely that technology interacts with caregiving, the built environment and a person's functional capacity in the home. Recognising the strong relationships across these elements holds the key to further analysis of introducing smart home technologies for older people in their own homes.

In addition to this, the case study analysis revealed new insights into the risks of introducing smart home technologies into the homes of older people ageing in place. These include the risks of:

- An older person's unwillingness to learn a new technology
- An older person's lack of confidence with technology

- inability to maintain the technology

- an older person taking a dislike to the technology due to frustration or fear

- an older person not being able to afford to continue to maintain or replace the technology

- a power outage - particularly when an older person is not trained to reset the technology

In summary, smart home technologies are a valuable exploration to complement Ageing in Place interventions including home modifications and existing informal and formal care services by working in the following ways:

- to facilitate self-care and autonomy by removing the need for third party intervention in order to complete daily tasks

- to support older people's safety in the home by automating tasks and reducing risk

- to support confidence levels in conducting daily tasks though increasing safety and reducing risk

There is evidence to suggest that they operate within the dynamics of the HAST model systematically developed in this paper and, along with the identified risks of introducing technology into older people's homes, warrant further longitudinal, scientific study.

\section{Further research}

This research highlights the need for a larger longitudinal study of technology, housing and caregiving for older people ageing in place. Research covered in the paper indicates that impacts on care, independence and wellbeing are likely to take place but there is currently no long-term data available. This is of course a large undertaking, given the great diversity of smart home technology that is continuing to the developed and introduced.

Further research is also warranted in the area of IoT technology to enable self-care of people as they age, particularly in the areas of home automation and home maintenance. Home maintenance and home tasks have been identified in the literature as being significant barriers to Ageing in Place (Fausset et al. 2011). IoT technologies have been developed in the area of appliance automation for smart homes that can be applied to a self-care model of ageing in place, however very little research has been conducted in this area.

Also, in all of the three cases, the idea of introducing the technology comes from a family member. In two of those cases the family member is at least one generation younger than the person for how the technology is intended. A suggestion for future research is to further explore who suggests or instigates new smart home 
technologies for older people and how does this contribute to the risk factors or the outcomes not being productive or positive for the older person?

\section{Abbreviations}

ANT: Actor network theory; EG: Environmental gerontology; HAS: Human activity space; HAST: Human activity space technology; loT: Internet of things

\section{Acknowledgements}

The author acknowledged the contribution of Catherine Donnelley who provided proofing services for the manuscript and template.

\section{Funding}

Not applicable

\section{Availability of data and materials}

Data is not able to be shared, as this would contravene the consent agreements made as part of the ethics and consent process.

\section{Authors' contributions}

The author read and approved the final manuscript.

\section{Ethics approval and consent to participate}

Ethics approval was granted by the Built Environment Human Research Ethics Panel (BEHREAP) of the University of New South Wales, Australia, with Ethics Approval number 125082

\section{Consent for publication}

All participants gave informed consent to have their responses published in a deidentified format. There are no images or videos presented.

\section{Competing interests}

The author declares that he/she has no competing interests.

\section{Publisher's Note}

Springer Nature remains neutral with regard to jurisdictional claims in published maps and institutional affiliations.

Received: 1 March 2018 Accepted: 29 October 2018

Published online: 06 December 2018

\section{References}

Australian Institute of Health and Welfare (2007) Australia's Welfare No. 8 Canberra: AlHW

Azimi, I., Rahmani, A. M., Liljeberg, P., \& Tenhunen, H. (2017). Internet of things for remote elderly monitoring: A study from user-centred perspective. Journal of Ambient Intelligence and Humanized Computing, 8(2), 273-289.

Bayer, A. H., \& Harper, L. (2000). Fixing to stay: A national survey of housing and home modification issues. AARP.

Beringer, R., Sixsmith, A., Campo, M., Brown, J., \& McCloskey, R. (2011). The "acceptance" of ambient assisted living: Developing an alternate methodology to this limited research lens. In International Conference on Smart Homes and Health Telematics (pp. 161-167). Berlin, Heidelberg: Springer.

Bijker, W. E. (1997). Of bicycles, bakelites, and bulbs: Toward a theory of sociotechnical change. MIT press.

Bloom, D. E., Chatterji, S., Kowal, P., Lloyd-Sherlock, P., McKee, M., Rechel, B., et al. (2015). Macroeconomic implications of population ageing and selected policy responses. The Lancet, 385(9968), 649-657.

Boldy, D., Grenade, L., Lewin, G., Karol, E., \& Burton, E. (2011). Older people's decisions regarding 'ageing in place': A Western Australian case study. Australasian Journal on Ageing, 30(3), 136-142.

Bridge, C. (2008). Computational case-based redesign for people with ability impairment: Rethinking, reuse and redesign learning for home modification practice. Saarbrucken: VDMI Verlag.

Cangiano, A., \& Shutes, I. (2010). Ageing, demand for care and the role of migrant care workers in the UK. Journal of Population Ageing, 3(1-2), 39-57.

Carnemolla, P., \& Bridge, C. (2011). Home Modifications and their impact on waged care substitution. UNSW, Sydney Australia: Home Modification Information Clearinghouse www.homemods.info
Carnemolla, P., \& Bridge, C. (2016). Accessible housing and health-related quality of life: Measurements of wellbeing outcomes following home modifications. ArchNet-IJAR, 10(2).

Carnemolla, P., \& Bridge, C. (2018). A scoping review of home modification interventions-mapping the evidence base. Indoor and Built Environment, $1420326 \times 18761112$

Cesta, A., Cortellessa, G., Rasconi, R., Pecora, F., Scopelliti, M., \& Tiberio, L. (2011). Monitoring elderly people with the robocare domestic environment: Interaction synthesis and user evaluation. Computational Intelligence, 27(1), 60-82.

Chatterji, S., Byles, J., Cutler, D., Seeman, T., \& Verdes, E. (2015). Health functioning, and disability in older adults_-Present status and future implications. The Lancet, 385(9967), 563-575.

Cresswell, K. M., Worth, A., \& Sheikh, A. (2010). Actor-network theory and its role in understanding the implementation of information technology developments in healthcare. BMC Medical Informatics and Decision Making, 10(1), 67.

Dodge, H. H., Mattek, N. C., Austin, D., Hayes, T. L., \& Kaye, J. A. (2012). In-home walking speeds and variability trajectories associated with mild cognitive impairment. Neurology, 78(24), 1946-1952.

Eckert, J. K. Morgan, L. A. \& Swamy, N. (2004). Preferences for receipt of care among community-dwelling adults. Journal of Aging \& Social Policy, 16(2), 49-65.

Fausset, C. B., Kelly, A. J., Rogers, W. A., \& Fisk, A. D. (2011). Challenges to aging in place: Understanding home maintenance difficulties. Journal of Housing for the Elderly, 25(2), 125-141.

Ghazal, B., \& Al-Khatib, K. (2015). Smart home automation system for elderly, and handicapped people using xbee. International Journal of Smart Home, 9(4), 203-210.

Gibson, G., Dickinson, C., Brittain, K., \& Robinson, L. (2015). The everyday use of assistive technology by people with dementia and their family carers: A qualitative study. BMC Geriatrics, 15(1), 89

Gill, A. Q., Phennel, N., Lane, D., \& Phung, V. L. (2016). IoT-enabled emergency information supply chain architecture for elderly people: The Australian context. Information Systems, 58, 75-86.

Gkouskos, D., \& Burgos, J. (2017). I'm in! Towards participatory healthcare of elderly through IOT. Procedia Computer Science, 113, 647-652.

Greenhalgh, T., Procter, R., Wherton, J., Sugarhood, P., Hinder, S., \& Rouncefield, M. (2015). What is quality in assisted living technology? The ARCHIE framework for effective telehealth and telecare services. BMC Medicine, 13(1), 91.

Gutierrez, F. J., Muñoz, D., Ochoa, S. F., \& Tapia, J. M. (2017). Assembling massmarket technology for the sake of wellbeing: A case study on the adoption of ambient intelligent systems by older adults living at home. Journal of Ambient Intelligence and Humanized Computing, 1-21.

lecovich, E. (2014). Aging in place: From theory to practice. Anthropological Notebooks, 20(1), 21-33.

Judd, B., Olsberg, D., Quinn, J., Groenhart, L., \& Demirbilek, O. (2010). Dwelling, land and neighbourhood use by older home owners. Australian Housing and Urban Research Institute (AHURI): Final Report. Melbourne.

Kaye, J. A., et al. (2011). Intelligent systems for assessing aging changes: homebased, unobtrusive, and continuous assessment of aging. Journals of Gerontology Series B: Psychological Sciences and Social Sciences, 66(1), i180i190.

Khoosal, D. I., \& Jones, P. H. (1989). Community care again: a need for definition. Juournal of the Royal Society of Medicine, Volume 82, p451-2.

Kleinberger, T., Jedlitschka, A., Storf, H., Steinbach-Nordmann, S., \& Prueckner, S. (2009, July). An approach to and evaluations of assisted living systems using ambient intelligence for emergency monitoring and prevention. In International Conference on Universal Access in Human-Computer Interaction (pp. 199-208). Berlin, Heidelberg: Springer.

Kontis, V., Bennett, J. E., Mathers, C. D., Li, G., Foreman, K., \& Ezzati, M. (2017). Future life expectancy in 35 industrialised countries: projections with a Bayesian model ensemble. The Lancet, 389(10076), 1323-1335.

Lawton, M. P.. \& Nahemow, L. (1973). Ecology and the aging process. In C. Eisdorfer \& M.P Powell (Eds), The Phsychology of adult development and aging (p.719) Washington DC: American Psychological Association.

Lee, C., \& Coughlin, J. F. (2015). PERSPECTIVE: Older adults' adoption of technology: an integrated approach to identifying determinants and barriers. Journal of Product Innovation Management, 32(5), 747-759.

Levin, L. S., Katz, A. H., \& Holst, E. (1976). Self-care: Lay initiatives in health (p. 133). New York: Prodist. 
Lorenz, K., Freddolino, P. P., Comas-Herrera, A., Knapp, M., \& Damant, J. (2017). Technology-based tools and services for people with dementia and carers: mapping technology onto the dementia care pathway. Dementia, 1471301217691617

Morris, M. E., Adair, B., Miller, K., Ozanne, E., Hansen, R., Pearce, A. J., et al. (2013). Smart-home technologies to assist older people to live well at home. Journal of Aging Science, 1(1), 1-9.

Nauha, L., Keränen, N. S., Kangas, M., Jämsä, T., \& Reponen, J. (2016). Assistive technologies at home for people with a memory disorder. Dementia, 1471301216674816

Parsons, F. (1909). Choosing a vocation. Boston, MA, USA: Houghton Mifflin.

Peek, S. T., Wouters, E. J., van Hoof, J., Luijkx, K. G., Boeije, H. R., \& Vrijhoef, H. J. (2014). Factors influencing acceptance of technology for aging in place: A systematic review. International Journal of Medical Informatics, 83(4), 235-248.

Peetoom, K. K., Lexis, M., Joore, M., Dirksen, C. D., \& De Witte, L. P. (2015). Literature review on monitoring technologies and their outcomes in independently living elderly people. Disability and Rehabilitation: Assistive Technology, 10(4), 271-294.

Pervin, L. A. (1968). Performance and satisfactionas a function o findividualenvironment fit. Psychological bulletin, 69(1), 56

Pietrzak, E., Cotea, C., \& Pullman, S. (2014). Does smart home technology prevent falls in community-dwelling older adults: A literature review. Journal of Innovation in Health Informatics, 21(3), 105-112.

Pope, A., \& Tarlov, A. (1991). Disability in America: Toward a national agenda for prevention. Washinton, DC: National Academy Press.

Procter, R., Greenhalgh, T., Wherton, J., Sugarhood, P., Rouncefield, M., \& Hinder, S (2014). The day-to-day co-production of ageing in place. Computer Supported Cooperative Work (CSCW), 23(3), 245-267.

Rantz, M. J., Skubic, M., Miller, S. J., Galambos, C., Alexander, G., Keller, J., \& Popescu, M. (2013). Sensor technology to support aging in place. Journal of the American Medical Directors Association, 14(6), 386-391.

Reeder, B., Meyer, E., Lazar, A., Chaudhuri, S., Thompson, H. J., \& Demiris, G. (2013). Framing the evidence for health smart homes and home-based consumer health technologies as a public health intervention for independent aging: A systematic review. International Journal of Medical Informatics, 82(7), 565-579.

Rhodes, J. (2009). Using actor-network theory to trace an ICT (telecenter) implementation trajectory in an African women's micro-enterprise development organization. USC Annenberg School for Communication, 5(3), $1-20$.

Sanders, C., Rogers, A., Bowen, R., Bower, P., Hirani, S., Cartwright, M., et al. (2012). Exploring barriers to participation and adoption of telehealth and telecare within the Whole System Demonstrator trial: a qualitative study. BMC health services research, 12(1), 220.

Satariano, W. A., Scharlach, A. E., \& Lindeman, D. (2014). Aging, place, and technology: Toward improving access and wellness in older populations. Journal of Aging and Health, 26(8), 1373-1389.

Schneider, B. (1987). $E=f(p, B)$ : The road to a radical approach to personenvirnment fit. Journal of Vocational Behaviour, 31 (3), 353-361.

Seuwou, P., Banissi, E., Ubakanma, G., Sharif, M. S., \& Healey, A. (2017, January). Actor-network theory as a framework to analyse technology acceptance model's external variables: The case of autonomous vehicles. In International Conference on Global Security, Safety, and Sustainability (pp. 305-320). Cham: Springer.

Sicari, S., Rizzardi, A., Miorandi, D., Cappiello, C., \& Coen-Porisini, A. (2016). Security policy enforcement for networked smart objects. Computer Networks, 108, 133-147.

Simonazzi, A. (2008). Care regimes and national employment models. cambridge. Journal of Economics, 33(2), 211-232.

Steinfeld, E., Schroeder, S., Duncan, J., Faste, R., Chollet, D., \& Bishop, M. (1979). Access to the built envirnent. A review of the literature. Washington DC: Government Printing Office.

Storni, C. (2010). Report on the "reassembling health workshop: Exploring the role of the internet of things". J. Participat Med.

Sun, H., De Florio, V., Gui, N., \& Blondia, C. (2009). Promises and challenges of ambient assisted living systems. In Information Technology: New Generations, 2009. ITNG'09. Sixth International Conference on (pp. 1201-1207) leee.

Van Der Geest, S. (1987). Self-care and the informal sale of drugs in South Cameroon. Soc Sci Med, 25(3), 293-305.

van Hoof, J., Kort, H. S. M., Rutten, P. G. S., \& Duijnstee, M. S. H. (2011). Ageing-inplace with the use of ambient intelligence technology: Perspectives of older users. International Journal of Medical Informatics, 80(5), 310-331.
Wahl, H. W., \& Weisman, G. D. (2003). Environmental gerontology at the beginning of the new millennium: Reflections on its historical, empirical, and theoretical development. The Gerontologist, 43(5), 616-627.

Wang, J., Carroll, D., Peck, M., Myneni, S., \& Gong, Y. (2016). Mobile and wearable technology needs for aging inplace: Perspectives from older adults and their caregivers and providers. In Nursing Informatics (pp. 486-490).

Wherton, J., Sugarhood, P., Procter, R., Hinder, S., \& Greenhalgh, T. (2015). Coproduction in practice: How people with assisted living needs can help design and evolve technologies and services. Implementation Science, 10(1), 75.

WHO Global Age-friendly Cities. (2007). A guide World Health Organization. Geneva: Switzerland.

Winance, M. (2010). Care and disability. Practices of experimenting, tinkering with and arranging people and technical aids. In A. Mol, I. Moser, \& J. Pols (Eds.), Care in practice: on tinkering in clinics, homes and farms. Transcript Verlag: Bielefeld.

Woolhead, G., Calnan, M., Dieppe, P., \& Tadd, W. (2004). Dignity in older age: What do older people in the United Kingdom think? Age and Ageing, 33(2), $165-170$.

World Health Organization. (1984). Health educaton in self-care: Possibilities and limitations. Geneva: World Health Organization.

Yan, L., Zhang, Y., Yang, L. T., \& Ning, H. (Eds.). (2008). The Internet of things: from RFID to the nextgeneration pervasive networked systems. CRC Press.

Yusif, S., Soar, J., \& Hafeez-Baig, A. (2016). Older people, assistive technologies, and the barriers to adoption: A systematic review. International journal of medical informatics, 94, 112-116.

\section{Submit your manuscript to a SpringerOpen ${ }^{\circ}$ journal and benefit from:}

- Convenient online submission

- Rigorous peer review

- Open access: articles freely available online

- High visibility within the field

- Retaining the copyright to your article

Submit your next manuscript at $\boldsymbol{\nabla}$ springeropen.com 